\title{
Trade-offs between size and energy reserves reflect alternative strategies for optimizing larval survival potential in rockfish
}

\author{
Rebecca Fisher ${ }^{1,2,3}$, Susan M. Sogard ${ }^{1, *}$, Steven A. Berkeley ${ }^{2}$ \\ ${ }^{1}$ National Marine Fisheries Service, 110 Shaffer Road, Santa Cruz, California 95060, USA \\ ${ }^{2}$ Long Marine Laboratory, 100 Shaffer Road, University of California, Santa Cruz, California 95060, USA \\ ${ }^{3}$ Present address: School of Marine Science and Technology, Claremont Road, University of Newcastle, \\ Newcastle Upon Tyne NE1 7RU, UK
}

\begin{abstract}
Reproductive strategies balancing offspring size and offspring number have been well documented in empirical tests of life-history theory. Here we found an additional trade-off between offspring size and offspring condition. Among 5 species of live-bearing rockfishes (Sebastes spp.) from central Californian populations, we observed a negative relationship between larval length at parturition and the size of their oil globule (a triacylglycerol-rich energy reserve). When compared with a variety of performance variables (resistance to starvation, growth, startle-escape performance and routine activity levels), it appears that this trade-off leads to a conflict when trying to optimize survival potential, with differing benefits to each trait. A large oil globule greatly increases resistance to starvation, whereas larger body size is associated with numerous performance benefits likely to synergistically decrease predation-based mortality and increase success at capturing prey (increased startle speeds and distances, as well as more rapid onset of growth and larger size at age). The tradeoff between energy reserves and body size is further reflected in the seasonal patterns of parturition of the 5 species, with larvae having large oil globules and small body size being released in winter, when productivity in the California Current is low but transport is generally onshore, and those with small oil globule reserves and large body size released in late spring, when productivity is high but transport is generally offshore. These 2 apparent reproductive strategies also reflect subgeneric phylogenetic relationships, suggesting a potential lineage-specific basis for the contrast in larval traits. The results highlight the importance of measuring both physical and performance traits of larvae, as well as considering multiple attributes of both, when evaluating progeny quality.
\end{abstract}

KEY WORDS: Life history trade-offs · Offspring size $\cdot$ Larval performance traits $\cdot$ Sebastes

\section{INTRODUCTION}

Life-history theory proposes that current reproductive strategies represent a compromise derived from selection on competing traits under constraints of phylogenetic history and limited environmental resources. The principle of allocation (Sibly \& Calow 1986) asserts that energy dedicated to one process comes at a cost of energy available for competing processes. For mature females, physiological trade-offs in traits associated with progeny are an inevitable conse- quence of finite energy reserves. For example, the allocation decision between offspring number and offspring size has been extensively examined (e.g. Smith \& Fretwell 1974, Parker \& Begon 1986, Elgar 1990, Roff 1992). In this trade-off, size is generally assumed to provide a valid index of fitness, encompassing additional offspring traits of growth, condition, and survival; numerous examples across a broad range of taxa support this assumption (Roff 1992, but see McEdward \& Morgan 2001). However, there are other dimensions to offspring fitness besides absolute size, and different 
larval traits may influence survival through competing mechanisms. Here we provide evidence that offspring size and offspring condition, as indexed by endogenous energy reserves, differentially influence a suite of performance capabilities, suggesting additional tradeoffs among offspring traits. Maternal investment may, therefore, involve a hierarchy of trade-offs, first associated with the total amount of energy devoted to individual offspring (as a trade-off with fecundity), and then with how that energy will be apportioned within each individual (e.g. as a trade-off between size and condition).

The reproductive life history expressed by an individual female is a function of complex interactions between her genotype and her environment. Genotypic effects reflect the full phylogenetic history of the female, with lineage-specific effects evident in traits that vary among but not within groups of related species, and microevolutionary processes evident in traits that vary among populations (Stearns 1992). Maternal age, condition and behavior can influence when and where progeny are released and how available resources are allocated among progeny. These maternal effects can translate environmental variation into phenotypic variation of offspring (Mousseau \& Fox 1998), but the magnitude of their influence may depend on the offspring's environment (Parichy \& Kaplan 1992, Einum \& Fleming 1999).

For marine fishes, mortality during their early life stages is typically very high, and small changes in mortality rates can have marked effects on survival of a cohort (Houde 1989). Because mortality is generally highest early in the larval phase (Cushing 1988) and decreases rapidly with increasing size (Miller et al. 1988), the characteristics of larvae at hatching or, for livebearers, when they are first released into the ocean may be crucial to subsequent survival. Numerous traits influence a larva's susceptibility to mortality and the subsequent recruitment success of a cohort. These traits include the initial physical aspects of the larvae at release, such as their size, stage of development, and physiological condition. Of equal importance are a large array of correlated performance variables, such as resistance to starvation, growth rate, escape responses and routine swimming speed. Little work has been completed to examine how these traits covary for closely related marine fishes; however, it is generally assumed that most performance-related traits critical to larval survival (e.g. resistance to starvation, growth and escape ability) will be an increasing function of initial larval size (Miller et al. 1988).

In this study, we evaluated larval life history characteristics of 5 species of rockfishes in the genus Sebastes. All Sebastes spp. are livebearers, with internal fertilization and sperm storage by females. Follow- ing fertilization, the egg and yolk sac stages are completed within the ovary. Larvae are released from their mothers at the first feeding stage, when they are still small (4 to $6 \mathrm{~mm}$ ) and highly vulnerable to starvation and predation, but developmentally capable of capturing and consuming prey. At parturition, the yolk sac is fully absorbed but endogenous energy is provided in an oil globule comprised of triacylglycerol (TAG)-rich lipids (Norton et al. 2001). Our prior work with black rockfish Sebastes melanops demonstrated that the oil globule has a striking influence on both the initial survival and growth of newly released larvae, and that there is a clear age-dependent maternal effect on oil globule size (Berkeley et al. 2004). Despite the potential importance of the oil globule, as well as initial larval size, to larval survival, no studies have examined how these parameters vary among congeners at parturition, or compared the extent to which they influence survival-related performance capabilities of larvae. Here we provide evidence that a trade-off exists between initial larval size and the size of their oil globule, and demonstrate how this compromise influences a variety of survival-related performance traits in Sebastes spp. larvae.

Sebastes is a highly speciose genus, with 72 species recorded in the coastal northeast Pacific (Love et al. 2002). The center of their diversity lies off southern California in a region of high seasonal upwelling. In this region, the livebearing reproductive pattern is thought to be an adaptation that reduces the period of time that eggs and larvae are exposed to the highly dynamic and unpredictable currents, jets, and transport processes characteristic of the California Current ecosystem (Parrish et al. 1981). An individual female typically develops only 1 brood per year, with larvae released in a single day. In central California, parturition primarily occurs in 1 of 2 time periods, winter (November to March) or spring (April to July) (Echeverria 1987). These 2 seasons span very different oceanographic regimes with contrasting circulation, upwelling and transport conditions and, perhaps most importantly, different conditions in food availability. Nearshore waters during the winter pre-upwelling period are influenced by poleward flow in the Davidson Current, onshore transport via frequent downwelling conditions, and relatively low levels of primary production (Lenarz et al. 1995, Pennington \& Chavez 2000). Following the spring transition, strong northwest winds enhance the equatorward flow of the California Current, transport is primarily offshore, and primary productivity is enhanced owing to upwelled, nutrient rich waters. Zooplankton biomass fluctuates in concordance with seasonal patterns of upwelling and nutrient influx (Roesler \& Chelton 1987). The increasing primary and secondary production following the spring transition presumably 
also supports an increased abundance of potential invertebrate and vertebrate predators. Thus, rockfish larvae released prior to the spring transition enter a pelagic environment favorable for retention in nearshore waters but potentially unfavorable for foraging opportunities, whereas larvae released after the transition encounter improved prey conditions but may be negatively impacted by offshore transport and increased predation risk.

\section{MATERIALS AND METHODS}

Adult females. Mature female rockfishes-blue Sebastes mystinus, gopher S. carnatus, kelp S. atrovirens, olive $S$. serranoides and yellowtail $S$. flaviduswere collected off central California from 2003 to 2006, prior to the anticipated period of larval release. Holding time in the laboratory prior to parturition ranged from 1 to $14 \mathrm{wk}$, with an average of $5 \mathrm{wk}$. Assuming a general Sebastes spp. gestation period of 30 to 50 d (Boehlert \& Yoklavich 1984, Boehlert et al. 1986, Eldridge et al. 2002), most of the females had already fertilized their eggs at the time of capture or did so soon after capture. Females were held singly in 5751 tanks in a flow-through seawater system with water temperatures maintained at $12^{\circ} \mathrm{C}\left( \pm 1^{\circ} \mathrm{C}\right)$. The temperatures experienced by pregnant females in the wild will be highly dependent on the occurrence of upwelling, but during the winter and spring parturition seasons, temperatures in the nearshore habitats used by these species will typically range from 10 to $14^{\circ} \mathrm{C}$ (Pennington \& Chavez 2000). Photoperiod matched ambient conditions for Monterey Bay's latitude, with an automated system providing dusk and dawn transitions and daily adjustment of day and night periods. All tanks were equipped with an air stone, and over- flow outlets were covered with $200 \mu \mathrm{m}$ nylon sieves to prevent extruded larvae from escaping. Adult fish were fed to satiation twice weekly with squid. Fish generally fed except during the last 1 to $2 \mathrm{wk}$ prior to parturition. Every morning, tanks were checked for evidence of extruded larvae. Parturition occurred at night for all individuals. Following parturition, adult females were sacrificed and measured for total length and wet mass (ovaries removed). The ovaries were examined for any remaining larvae, and if found, these were retained and included with the fecundity sample (see below). Sagittal otoliths were removed and used to determine the age of each female using the breakand-burn method described by Laidig et al. (2003). Samples of larvae were taken and used for the measurement of numerous physical and performance traits (described below). Larvae of yellowtail rockfish were measured for physical traits but were not analyzed in performance tests owing to time and space constraints. Maternal traits of size, age, and fecundity are listed in Table 1.

Physical traits. Fecundity: All larvae remaining in the extrusion tank were siphoned through a $200 \mu \mathrm{m}$ sieve and preserved in $95 \%$ EtOH. Fecundity for each female was estimated using multiple divisions with a plankton splitter. Initially the whole sample was divided twice (creating 4 equal sub-samples). Each of these 4 subsamples was independently split a further 3 to 7 times (depending on the size of the sample), and the final split samples from each were counted under a dissecting microscope using a gridded petri dish. Fecundity was calculated by averaging the counts of the 4 subsamples and dividing by the proportion counted. The number of larvae removed from the tank for various other measurements (see below) was added to this fecundity estimate in order to obtain total fecundity estimates for each female.

Table 1. Sebastes spp. Summary statistics (mean \pm SD and range) for female rockfishes - blue S. mystinus, gopher $S$. carnatus, kelp $S$. atrovirens, olive $S$. serranoides, and yellowtail $S$. flavidus-that produced larvae used in comparisons of physical and performance traits

\begin{tabular}{|c|c|c|c|c|c|}
\hline & $\begin{array}{l}\text { Blue } \\
\mathrm{n}=40\end{array}$ & $\begin{array}{c}\text { Gopher } \\
\mathrm{n}=28\end{array}$ & $\begin{array}{c}\text { Kelp } \\
\mathrm{n}=25\end{array}$ & $\begin{array}{l}\text { Olive } \\
\mathrm{n}=9\end{array}$ & $\begin{array}{l}\text { Yellowtail } \\
\mathrm{n}=33\end{array}$ \\
\hline Total length (mm) & $\begin{array}{c}292 \pm 24 \\
(257-352)\end{array}$ & $\begin{array}{c}293 \pm 20 \\
(255-340)\end{array}$ & $\begin{array}{c}311 \pm 19 \\
(275-352)\end{array}$ & $\begin{array}{l}361 \pm 28 \\
(330-415)\end{array}$ & $\begin{array}{c}439 \pm 33 \\
(373-512)\end{array}$ \\
\hline Weight (g) & $\begin{array}{c}378 \pm 94 \\
(242-674)\end{array}$ & $\begin{array}{l}500 \pm 111 \\
(354-792)\end{array}$ & $\begin{array}{c}484 \pm 80 \\
(318-634)\end{array}$ & $\begin{array}{l}597 \pm 170 \\
(478-984)\end{array}$ & $\begin{array}{l}1176 \pm 251 \\
(778-1822)\end{array}$ \\
\hline Age (yr) & $\begin{array}{c}8 \pm 4 \\
(4-21)\end{array}$ & $\begin{array}{l}10 \pm 3 \\
(7-22)\end{array}$ & $\begin{array}{l}12 \pm 5 \\
(6-21)\end{array}$ & $\begin{array}{l}6 \pm 2 \\
(4-9)\end{array}$ & $\begin{array}{l}15 \pm 5 \\
(8-25)\end{array}$ \\
\hline Fecundity $(\times 1000)$ & $\begin{array}{c}112 \pm 109 \\
(16-428)\end{array}$ & $\begin{array}{l}107 \pm 39 \\
(43-178)\end{array}$ & $\begin{array}{l}134 \pm 75 \\
(38-341)\end{array}$ & $\begin{array}{l}115 \pm 73 \\
(18-223)\end{array}$ & $\begin{array}{c}234 \pm 135 \\
(48-454)\end{array}$ \\
\hline Parturition date & $\begin{array}{c}\text { Feb } 9 \pm 18 d \\
(\text { Dec } 27-\text { Mar } 8)\end{array}$ & $\begin{array}{c}\text { Apr } 22 \pm 17 \text { d } \\
\text { (Mar 22-May 31) }\end{array}$ & $\begin{array}{l}\text { May } 21 \pm 14 \text { d } \\
\text { (Apr 22-Jun 19) }\end{array}$ & $\begin{array}{l}\text { Feb } 13 \pm 16 \text { d } \\
(\text { Jan 16-Mar 9) }\end{array}$ & $\begin{array}{c}\text { Feb } 23 \pm 15 \mathrm{~d} \\
(\operatorname{Jan} 16-\text { Mar 20 }\end{array}$ \\
\hline
\end{tabular}


Body size and oil globule size: On the morning following parturition, 20 to 30 larvae were randomly selected from the tank and digitally photographed under a dissecting microscope. A light anesthetic of MS-222 was used to reduce movement during image collection. Images were subsequently analyzed using the Optimas program to measure notochord length, body depth (immediately behind the gut) and oil globule diameter for individual larvae. The volume of the oil globule (an assumed sphere) was calculated from the diameter. Only images of live larvae were used for measurements in order to minimize problems associated with shrinkage. Data analyses were based on the mean measurements of the 20 to 30 randomly selected larvae from each female.

Performance traits. Resistance to starvation: Larvae from blue, gopher, kelp, and olive rockfish were tested for their survival in the absence of food. Two replicate samples for each female of 500 (2003 experiments) or 200 larvae (2004 experiments) were transferred to black 501 tanks painted on the bottom with non-toxic white paint to aid subsequent counting of dead larvae. Care was taken to ensure larvae were submersed in water at all times and never came in contact with anything solid, and that any turbulence associated with handling was minimized. Water temperatures were maintained at $12^{\circ} \mathrm{C}\left( \pm 1^{\circ} \mathrm{C}\right)$ in a flow-through seawater system with gentle aeration and very low flow $(2 \mathrm{ml}$ $\mathrm{s}^{-1}$ ) of filtered seawater. Larvae were not fed. Tanks were checked daily and dead larvae were counted and removed. The time elapsed (d) until $75 \%$ of larvae were dead was recorded. Although a metric of $50 \%$ mortality was used in experiments for black rockfish (Berkeley et al. 2004), the more rapid starvation mortality displayed by some of the species in this study necessitated an extended time period to allow distinction among species.

Growth: Larval growth rates were examined for blue, gopher, and kelp rockfish. A sample of 6000 larvae was transferred to separate $300 \mathrm{l}$ black rearing tanks for each female and maintained at $12^{\circ} \mathrm{C}\left( \pm 1^{\circ} \mathrm{C}\right)$ using flow-through filtered seawater and gentle aeration. Overflow outlets were covered using $200 \mu \mathrm{m}$ nylon sieves to prevent larvae from escaping. Tanks were illuminated using fluorescent daylight bulbs. Each morning, $15 \mathrm{ml}$ of concentrated microalgae (a mixture of Nannochloropsis sp. and Isochrysis sp.) was added to each tank. This green culture technique provided a gradient of light intensity, allowing larvae to select a preferred light level, and provided nutrition for larval prey. Larvae were fed laboratory-cultured rotifers (mean size $80 \mu \mathrm{m}$ ) that were maintained on a diet of concentrated Nannochloropsis sp. and were enriched overnight with Isochrysis sp. before being fed to larvae. Rotifer densities in rearing tanks were main- tained at a minimum of $2 \mathrm{ml}^{-1}$. Every $4 \mathrm{~d}, 5$ larvae were randomly sampled and measured live, following the protocol described for initial larval length and body depth. Growth was monitored for the first $28 \mathrm{~d}$ of larval life. Mortality rates were typically high in the growth tanks, limiting the number of broods that could be examined. Larval size and body depth were plotted as a function of age for larvae from each female. Growth was examined in terms of both standard length as an estimate of skeletal growth, as well as body depth (measured just behind the gut) as an estimate of the height of the muscle mass. Visual inspection of growth plots indicated a split-plot response in many cases, with limited or sometimes negative growth in the first few days of life and positive growth thereafter. This growth lag was estimated in days for larvae from each female. For the subsequent period of positive growth, least-squares regressions were fitted to determine the daily growth rate. Variables included in evaluation of growth performance included growth lag (d), the slopes of the regressions of length and body depth against time after the onset of positive growth, and the mean size of larvae at $28 \mathrm{~d}$.

Startle response: The reaction of larvae to a simulated attack was examined in blue, gopher, kelp, and olive rockfish larvae. A sample of 10 larvae at parturition was transferred to a $10 \times 10 \mathrm{~cm}$ filming tank with opaque black sides and a clear bottom, housed in a quiet area in a slow-flowing water bath (temperature = $12 \pm 1^{\circ} \mathrm{C}$ ). The filming tank was filled with fresh seawater to a depth of $2 \mathrm{~cm}$, and a few drops of concentrated Nannochloropsis sp. added to lower water clarity and reduce stress on the larvae. The filming area was illuminated indirectly using 2 fluorescent lights. Larvae were filmed from underneath the tank using a black and white video camera (Sony model SSCM383) connected to a VCR. Larvae were allowed to acclimate for $15 \mathrm{~min}$, and then were filmed for $5 \mathrm{~min}$ undisturbed to record their routine swimming speed and activity. Larvae were then 'startled' using a fine metal probe that was inserted in the tank and slowly moved toward a larva's head. After startling, larvae were left for another 15 min to recover and then were startled a second time. Several individuals within the central region of the arena were startled for each trial. We were not able to distinguish which individuals were startled in subsequent trials.

During video playback, individual startle sequences were digitally captured field-by-field using a Panasonic AG 1980 S-VHS VCR and a Pinnacle Studio MP10 capture card ( 60 fields s ${ }^{-1}$ resolution). Captured sequences were then analyzed using Tema Trackeye motion analysis software, and the $x, y$ position (in pixels) of the larva's head was recorded every time step. Using these data, calculations were made of the 
total distance covered by the larvae from the start to the end of the startle response, the maximum speed attained during the startle, and the average swimming speed throughout the startle. A 2-step moving average was used for calculations. Because of the relatively low temporal resolution, our index of maximum startle speed may underestimate the actual maximum achieved, but should provide a reasonable relative measure among individuals. Similar frame rates have been found to be suitable for measuring overall startle speed and distance (Harper \& Blake 1990). The average swimming speed of larvae in pixels was calculated from the $x, y$ position of larvae over time. Measurements in pixels were converted to mm using a scale that was placed at the base of the filming tank before and after filming.

Routine activity: To measure routine activity of the larvae used for measurement of startle responses, the preliminary 5 min undisturbed filming period was captured (30 frames $\mathrm{s}^{-1}$ resolution). Larvae present in the field of view were tracked, with swimming speeds calculated as for startle speed, using a 2-step moving average. In addition, the percentage of time larvae spent 'inactive' was calculated based on all frames in which larvae moved at a speed of less than $1 \mathrm{~mm} \mathrm{~s}^{-1}$. Average routine speeds were calculated using only frames in which larvae were considered 'active'. An average of at least 10 individual measurements for larvae from each female was used in subsequent analyses for both startle and routine speed.

Data analysis. For all analyses, the unit of replication was the adult female, with all physical and performance measurements averaged across her larvae. Sample sizes were greater for physical traits than performance traits owing to logistical limitations in conducting performance experiments. All sample sizes for each trait are reported in Tables $1 \& 2$. Preliminary analyses indicated that physical and performance traits did not differ among years of collection for females within a species; therefore, all females were combined for species comparisons. ANOVA was used to test for differences among species in the physical traits of larvae (initial larval length, initial larval body depth and initial oil globule volume) and their starvation resistance (time to $75 \%$ mortality). Multivariate ANOVA (MANOVA) was used to assess species differences in performance traits with multiple variables, including startle response (with variables of escape distance, average speed, and maximum speed), growth (lag in length and depth, subsequent daily growth in length and depth), size at 1 mo of age (length and depth), and routine activity (average undisturbed speed and time spent inactive). Tukey's tests following univariate ANOVAs were used as post-hoc tests to determine pairwise differences between individual species.
Parturition timing of each of the 5 species was compared with the local pattern of upwelling and zooplankton abundance. For upwelling, we used data provided by the Pacific Fisheries Environmental Laboratory, NOAA (www.pfeg.noaa.gov/products/current_ products.html). From their modeled time series (1946 to 2006), we calculated the mean monthly Bakun index of upwelling at $36^{\circ} \mathrm{N}, 122^{\circ} \mathrm{W}$, the approximate location of adult collections. For zooplankton abundance, we used the monthly mean biomass calculated for California Cooperative Oceanic Fisheries Investigations (CalCOFI) collections from 1951 to 1982 by Roesler \& Chelton (1987), derived from their Fig. 6 for Region 4, which extends along the central California coast from San Francisco Bay to Point Conception.

\section{RESULTS}

\section{Physical traits}

At parturition, larvae within a brood were similar in development, suggesting a common fertilization date and development schedule. The mean size of larvae from each female for the 5 species combined ranged from 4.30 to $5.55 \mathrm{~mm}$ in notochord length and 0.28 to $0.39 \mathrm{~mm}$ in body depth. The oil globule ranged from 0.021 to $0.188 \mathrm{~mm}$ in diameter, resulting in volumes of 0.000007 to $0.003522 \mathrm{~mm}^{3}$. Despite this relatively narrow range in physical dimensions, there were significant differences among the 5 species (Tables 2 \& 3). Among species, there was a significant trend of increasing oil globule size with decreasing larval length $\left(r^{2}=0.84, p=0.030, n=5\right.$, Fig. 1). Blue, olive, and yellowtail rockfish larvae had similarly sized oil globules that were approximately 4 times the volume of those in gopher and kelp rockfish larvae, which did not differ significantly from each other. Gopher rockfish larvae were significantly larger in notochord length than all other species, and kelp and olive rockfish were significantly larger than blue and yellowtail, which did not differ significantly. Body depth was correlated with length and exhibited comparable differences among species (Tables $2 \& 3$ ). Within species, there was no trend between larval length and oil globule volume (all $\mathrm{p}>0.17)$.

There was no significant difference in weightspecific fecundity (larvae per $g$ female body weight) among the 5 species $\left(F_{4,55}=1.02, \mathrm{p}=0.404\right)$. Within species, there was a significant positive correlation of weight-specific fecundity with notochord length for olive rockfish $\left(\mathrm{n}=7, \mathrm{r}^{2}=0.83, \mathrm{p}=0.004\right)$. Fecundity was neither related to larval size in the other species, nor to oil globule volume in any of the species examined. 


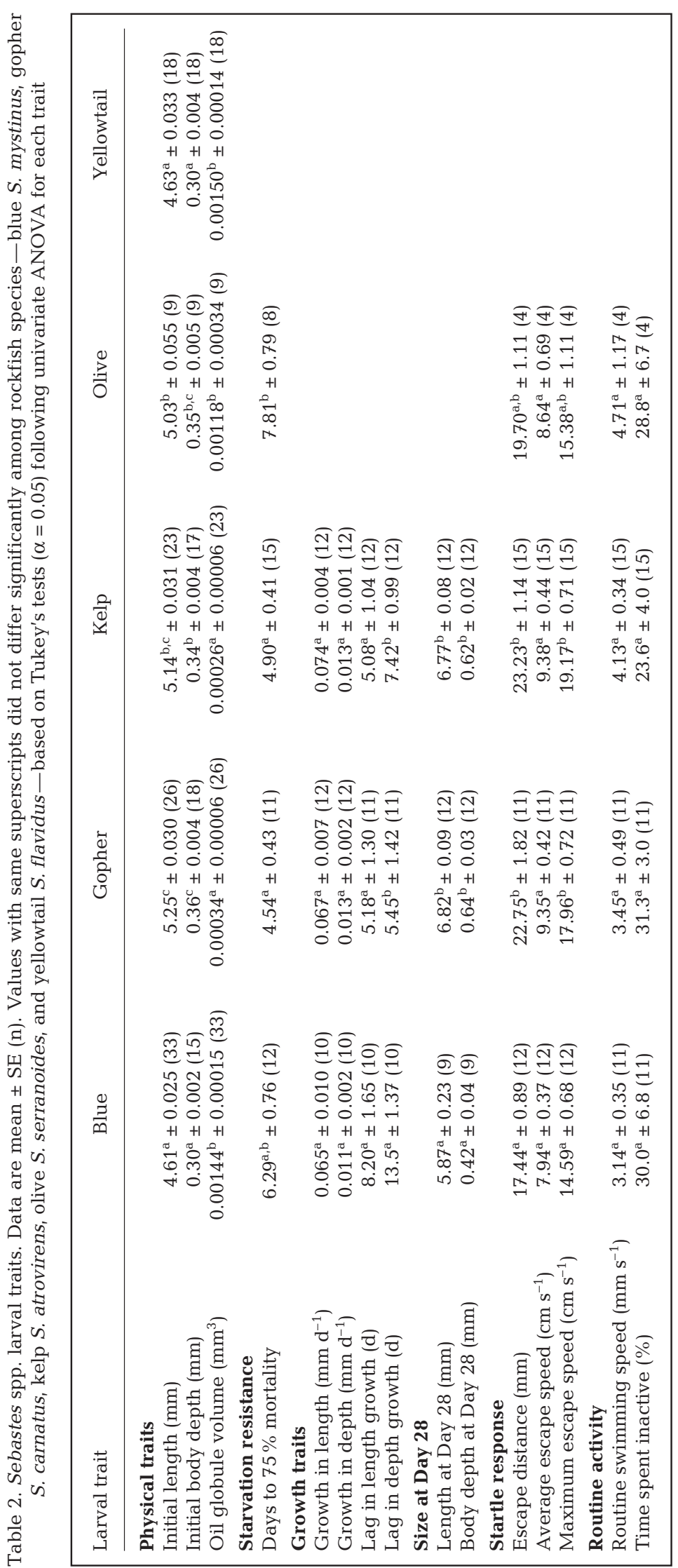

\section{Performance traits}

Starvation resistance

In the absence of food, larval rockfish survived from 2 to $12 \mathrm{~d}$ before $75 \%$ of the cohort had died. Significant differences among species were evident, with gopher and kelp rockfish having lower starvation resistance than olive rockfish, and blue rockfish having intermediate resistance (Tables 2 \& 3). Starvation resistance was a clear function of oil globule size both within and among species (Fig. 2). For all 4 species, broods with large oil globules were able to resist starvation about 3 times longer than broods with small oil globules. The correlation between mortality and oil globule volume was significant within species for blue $(p=0.003)$, olive $(p<0.001)$ and gopher rockfish $(p=0.049)$, and marginally non-significant for kelp rockfish $(p=0.084)$.

\section{Growth patterns}

A time lag before initiation of positive growth was common for all species, and on average ranged from 0 to $22 \mathrm{~d}$ for the lag in growth in body depth and 0 to $14 \mathrm{~d}$ for the lag in growth in length. Growth rates after the initial lag were slow overall, ranging from 0.021 to $0.124 \mathrm{~mm} \mathrm{~d}^{-1}$ for notochord length and 0.006 to $0.024 \mathrm{~mm} \mathrm{~d}^{-1}$ in body depth. MANOVA comparing traits of lag time and growth rate indicated significant differences among species (Table 3). Univariate tests of the 4 growth traits found that only the lag in growth in body depth differed among species, with a longer lag for blue than for kelp or gopher rockfish (Table 2).

The initially smaller size of blue rockfish larvae and the greater lag prior to positive growth resulted in a significantly smaller size at age $28 \mathrm{~d}$ compared with gopher and kelp rockfish (Table 2, Fig. 3). In general, as larvae approached flexion, growth in body depth accelerated relative to growth in length. Gopher and kelp rockfish were entering this phase of growth at $28 \mathrm{~d}$, resulting in body depths that were about $50 \%$ larger than those of blue rockfish larvae. In contrast, at parturition, gopher and kelp larvae were only about $15 \%$ larger in depth than blue rockfish. For length, kelp and gopher rockfish were about $12 \%$ larger than blue rockfish at parturition 
Table 3. Sebastes spp. Results of statistical comparisons among species of larval rockfish physical and performance traits. $F$-ratios for MANOVA tests are Wilk's $\lambda$

\begin{tabular}{|lcccc|}
\hline Larval trait & Test & df & F-ratio & $\mathrm{p}$ \\
\hline $\begin{array}{l}\text { Initial length } \\
(\mathrm{mm})\end{array}$ & ANOVA & 4,104 & 100.5 & $<0.001$ \\
$\begin{array}{l}\text { Initial body depth } \\
(\mathrm{mm})\end{array}$ & ANOVA & 4,72 & 50.7 & $<0.001$ \\
Oil globule volume & ANOVA & 4,104 & 20.5 & $<0.001$ \\
$\left(\mathrm{~mm}^{3}\right)$ & & & & \\
$\begin{array}{l}\text { Days to 75\% } \\
\text { mortality }\end{array}$ & ANOVA & 3,42 & 5.4 & 0.003 \\
$\begin{array}{l}\text { Growth traits } \\
\text { Size at Day 28 }\end{array}$ & MANOVA & 8,54 & 3.7 & 0.002 \\
Startle response & MANOVA & 4,58 & 6.8 & $<0.001$ \\
Routine activity & MANOVA & 9,87 & 2.8 & 0.006 \\
& & 6,72 & 1.1 & 0.362 \\
\hline
\end{tabular}

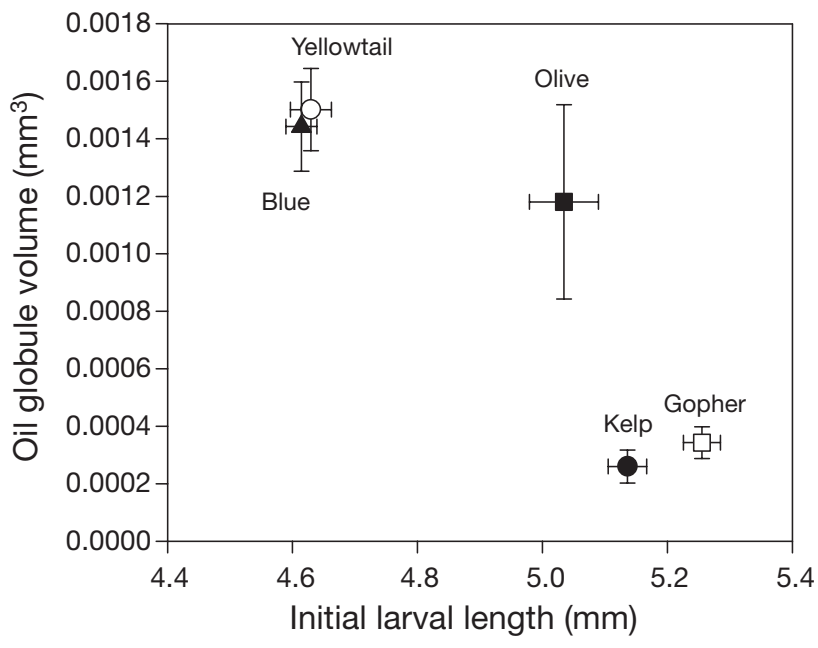

Fig. 1. Sebastes spp. Mean $( \pm \mathrm{SE})$ oil globule volume and notochord length for larvae of 5 species of rockfishes-blue $S$. mystinus, gopher $S$. carnatus, kelp $S$. atrovirens, olive $S$. serranoides, yellowtail $S$. flavidus-at the time of parturition. Sample sizes noted in Table 2

and about $15 \%$ larger at age $28 \mathrm{~d}$. Thus, species differences in size were not only maintained for the first $28 \mathrm{~d}$, they also increased.

\section{Startle response}

Rockfish larvae responded to the stimulation of an approaching probe with classic 'C start' behavior common to many larval teleosts (Eaton \& DiDomenico 1986). The body first curled into a $C$ shape, and then rapidly accelerated into a straightened position as the larva moved away from the stimulus. The average

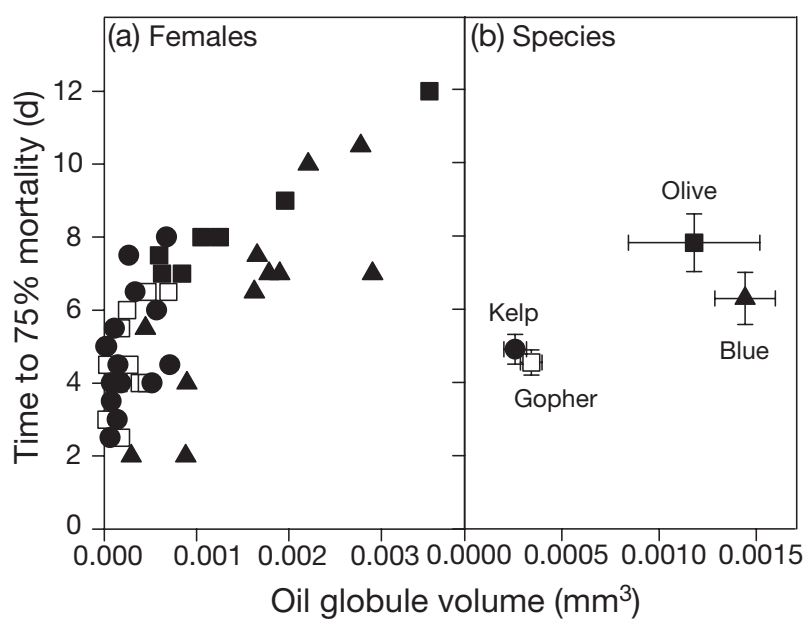

Fig. 2. Sebastes spp. Starvation resistance for larvae of 4 species of rockfishes - blue $S$. mystinus, gopher $S$. carnatus, kelp $S$. atrovirens, olive $S$. serranoides - relative to the size of the oil globule at parturition. Values are (a) mean number of days elapsed prior to $75 \%$ mortality of larvae from 2 replicate tanks for each female and $(b)$ the average $( \pm \mathrm{SE})$ of all females for each species. Sample sizes noted in Table 2
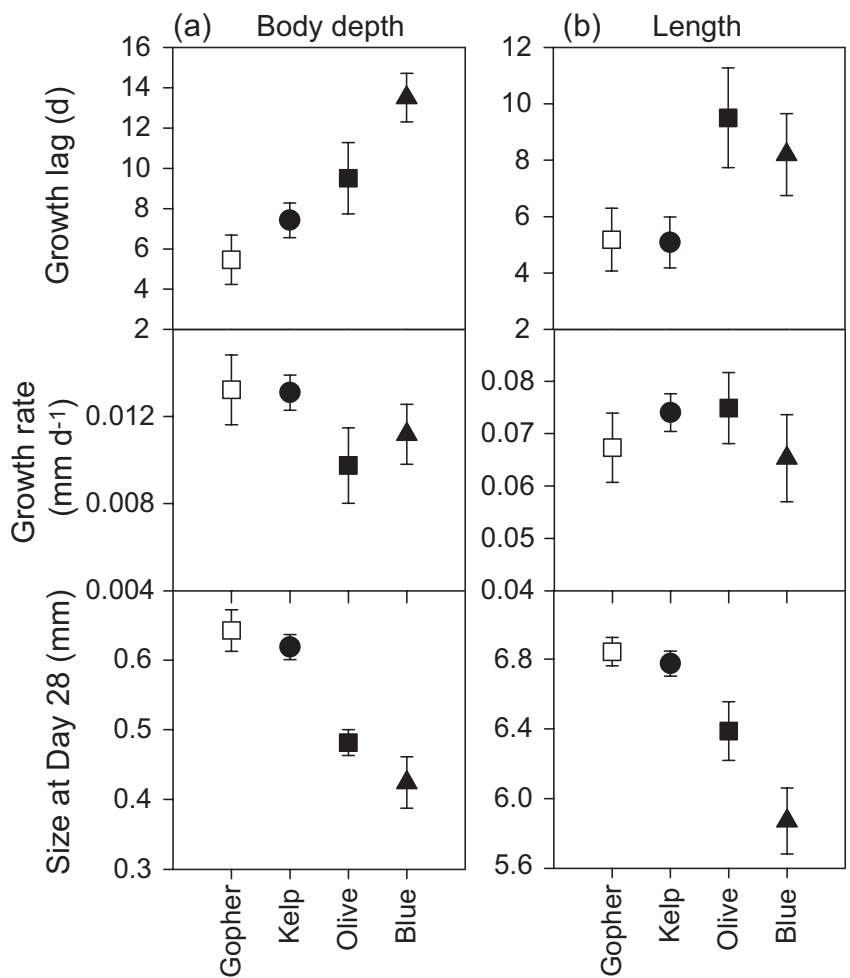

Fig. 3. Sebastes spp. Mean $( \pm \mathrm{SE})$ value of larval growth traits, including the lag in time since parturition prior to positive growth (d), the subsequent daily growth rate $\left(\mathrm{mm} \mathrm{d}^{-1}\right)$, and the size of larvae at age $28 \mathrm{~d}$ for 4 species of rockfishes-blue $S$. mystinus, gopher $S$. carnatus, kelp $S$. atrovirens, olive $S$. serranoides. Values for olive rockfish were included for graphical comparison, but were not included in statistical analyses owing to low sample size $(n=2)$. Values are shown for (a) body depth and (b) length. Sample sizes noted in Table 2 

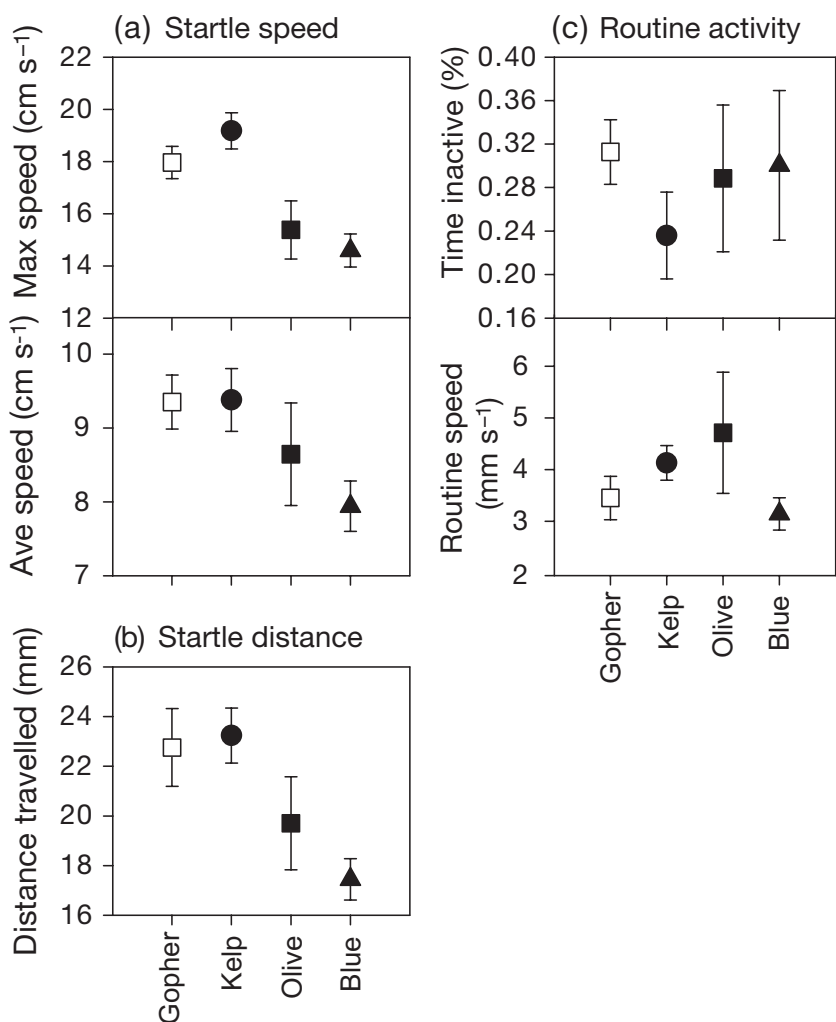

Fig. 4. Sebastes spp. Mean $( \pm \mathrm{SE})$ value of larval performance traits of startle responses. (a) Average escape speed and maximum escape speed $\left(\mathrm{cm} \mathrm{s}^{-1}\right)$, (b) escape distance $(\mathrm{mm})$, and (c) routine activity (routine speed in $\mathrm{mm} \mathrm{s}^{-1}$, and \% time spent inactive) for 4 species of rockfishes - blue $S$. mystinus, gopher $S$. carnatus, kelp $S$. atrovirens, olive $S$. serranoidesat time of parturition. Sample sizes noted in Table 2

distance covered by this response ranged from 10 to $32 \mathrm{~mm}$ across cohorts, with an average speed of 5 to $13 \mathrm{~cm} \mathrm{~s}^{-1}$ (10 to 24 body lengths [bl] s${ }^{-1}$ ) and a maximum speed of 9 to $25 \mathrm{~cm} \mathrm{~s}^{-1}$ ( 20 to $46 \mathrm{bl} \mathrm{s}^{-1}$ ). The 3 variables measured in association with the escape response together demonstrated significant differences among species (MANOVA; Fig. 4, Table 3). Univariate tests revealed that blue rockfish larvae had a significantly shorter escape distance and lower maximum speed compared with kelp and gopher rockfish, and that olive rockfish were intermediate in response capabilities.

\section{Routine activity}

When left undisturbed, rockfish larvae spent much of their time remaining still without active movement. The percentage of time spent being inactive varied widely, ranging from 4 to $80 \%$ among cohorts. When actively moving, rockfish larvae maintained average swimming speeds of 1.5 to $7.5 \mathrm{~mm} \mathrm{~s}^{-1}$. Routine activity levels did not differ among the 4 species (MANOVA; Fig. 4, Table 3).

\section{Parturition timing}

For the females used in our experiments, larval extrusion occurred within the season normally expected for central California based on the literature (Echeverria 1987, Love et al. 2002). Blue, yellowtail, and olive rockfish released larvae during winter months, prior to the initiation of upwelling and peak zooplankton abundance (Fig. 5). In contrast, gopher and kelp rockfish released larvae in late spring, when both upwelling and zooplankton abundance typically approach seasonal peaks. There was no overlap in parturition timing between the winter and spring species in our experiments. Thus, species that spawned in winter had relatively large oil globules, in contrast to species that spawned in spring, which had a relatively large body size. A negative relationship between parturition date and oil globule volume was also observed within species for blue $\left(\mathrm{r}^{2}\right.$ $=0.37, \mathrm{p}<0.001)$ and olive $\left(\mathrm{r}^{2}=0.67, \mathrm{p}<0.001\right)$ rockfish, and was marginally non-significant for gopher rockfish $\left(r^{2}=0.13, p=0.071\right)$, but was not observed for yellowtail or kelp rockfish. There was no trend between larval length and parturition date within species.

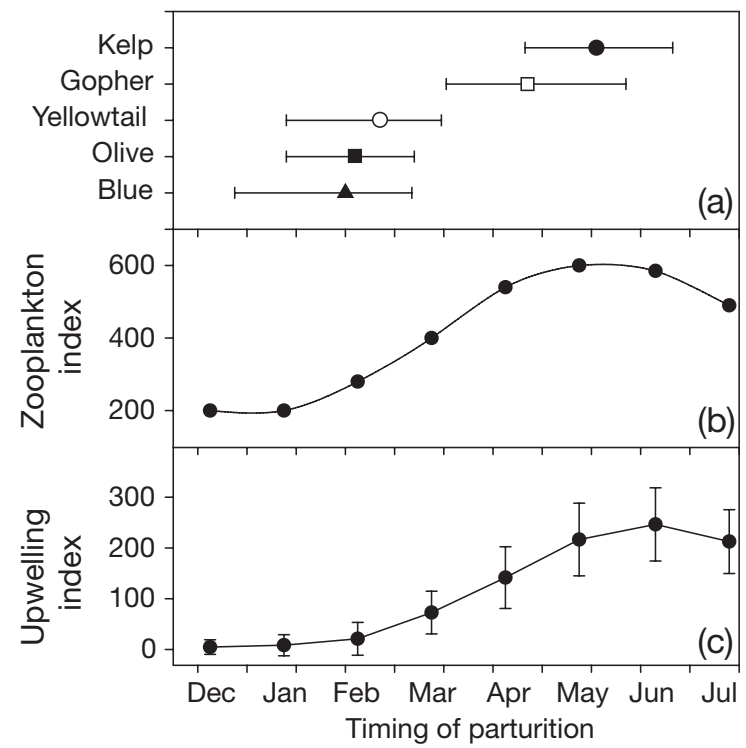

Fig. 5. Sebastes spp. (a) Mean and range of parturition dates for 5 species of rockfishes - blue $S$. mystinus, gopher $S$. carnatus, kelp $S$. atrovirens, olive $S$. serranoides, yellowtail $S$. flavidus - that released larvae in laboratory experiments,

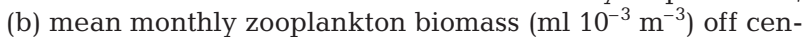
tral California coast (derived from Roesler \& Chelton 1987), and (c) mean $\left( \pm \mathrm{SD}\right.$ ) monthly Bakun upwelling index at $36^{\circ} \mathrm{N}$, $122^{\circ} \mathrm{W}$ (Monterey Bay) from 1946 to 2006 


\section{DISCUSSION}

\section{Trade-offs between size and energy reserves}

Absolute size is typically presumed to provide a valid index of offspring quality, and in general there are likely to be strong positive correlations among size and other survival-enhancing traits (Kaplan 1980, Miller et al. 1988, Berg et al. 2001, Moran \& Emlet 2001). However, in rockfish larvae, a trade-off between body size and energy reserves in the oil globule is evident across species. This trade-off in initial composition of larvae appears to underlie species differences in subsequent performance. Large oil globules provide a clearly enhanced resistance to starvation, whereas larger body size is associated with improved performance in growth and escape responses. Blue rockfish larvae, with large oil globules but small body size, have a high resistance to early starvation but initiate positive growth relatively late, have a small size at age $28 \mathrm{~d}$, and relatively poor startle performance. In contrast, gopher and kelp rockfish larvae are larger than blue rockfish at parturition, and this difference is maintained and even enhanced after a $28 \mathrm{~d}$ period. Gopher and kelp rockfish have better escape performance than blue rockfish, but poor survival in the absence of food, consistent with their small energy reserves. Thus, gopher and kelp rockfish are equipped with performance capabilities that are likely to synergistically improve prey capture and predator avoidance, but they must begin feeding soon after parturition or risk early starvation. Although we did not have sufficient growth data for olive rockfish to allow comparison with the other species, their high starvation resistance and intermediate startle response were consistent with their large oil globules and intermediate body size. Larvae with substantial endogenous lipid reserves have a longer time frame over which they can encounter and take advantage of favorable environmental conditions before exogenous feeding is required. Such larvae are likely to do better than those with limited energy reserves in environments where prey densities are highly variable and starvationbased mortality is high (Letcher et al. 1996). In contrast, when food is not limiting, predation is believed to be the dominant source of mortality (Letcher et al. 1996) and selection for larger size and faster growth rates should be favored. Together these results suggest that, for rockfish, survival potential may be contextdependent, and that offspring size provides an incomplete index of fitness.

The trade-off between larval size and larval condition was significant among species but not within species. This may be due to the limited range of variation in larval length: within a species, the coefficient of variation $(\mathrm{CV})$ for length ranged from only $2.8 \%$ (kelp rockfish) to $3.3 \%$ (olive rockfish) across the mean values we calculated for each female in this study. In contrast, the CV for oil globule volume ranged from $40 \%$ (yellowtail rockfish) to $106 \%$ (kelp rockfish). The similarity in larval length for the broods of different females limits the potential for expression of trade-offs of length with other traits within a species.

\section{Timing of parturition}

For all species examined here, the trade-off between energy reserves and body size was further reflected in the seasonal patterns of parturition. Species with large oil globules (blue, olive, and yellowtail) released larvae in winter, with parturition dates from late December to early March. Species with small oil globules but relatively large body size (gopher and kelp) released larvae in spring, with parturition dates from late March to early June. These 2 apparent strategies in larval provisioning may be associated with the environment into which larvae are released. Large-scale seasonal patterns in oceanography throughout the California Current ecosystem result in contrasting conditions of transport and primary productivity. In winter, potential advective loss via upwelling is reduced (Parrish et al. 1981), but primary production is also relatively low (Pennington \& Chavez 2000). Following the spring transition, upwelling increases nutrient input into coastal waters, and production accelerates. The contrast in secondary production between winter and spring is particularly striking in the central California coast region; based on a 32 yr time series, Roesler \& Chelton (1987) noted a tripling of average zooplankton biomass between January and May. Increased production of invertebrate and vertebrate predators of ichthyoplankton is expected in conjunction with increased secondary production. These trade-offs lead to the conclusion that for winter spawners the benefits of starvation resistance provided by greater levels of lipid reserves appear to outweigh the presumed benefits of larger body size, and vice versa for spring spawners. These effects are subtle: a large oil globule, for example, can only extend starvation resistance for 1 or $2 \mathrm{wk}$, suggesting that parturition timing must still provide an appropriate match to environmental conditions.

In the present study, we hypothesized that offshore transport has a negative impact on larval survival (Parrish et al. 1981, Shanks \& Eckert 2005). Transport effects may, however, vary with ontogenetic stage. Little is known about the capabilities of newly extruded rockfish larvae to modify transport through vertical migration behavior. Early stage larvae appear to occur primarily above the pycnocline with no diel 
pattern (Sakuma et al. 1999, Bjorkstedt et al. 2002), suggesting little vertical migration. Later larval and pelagic juvenile stages are found throughout the water column and may be capable of selecting desired depths (Ross \& Larson 2003). The timing of oceanographic patterns may also be important. For example, during El Niño events, retention in nearshore waters may enhance survival of early post-parturition stages, yet decrease survival of later-stage larvae and juveniles that would typically be transported offshore when upwelling begins (Yoklavich et al. 1996).

Likewise, little is known about the predators of newly released rockfish larvae, though they likely include a broad suite of invertebrates and small fishes. As primary and secondary production accelerate during spring, predator abundances should also increase. The extent to which predation risk increases for rockfish larvae will depend on encounter rates and the availability of alternate prey, as well as the time lag of predator abundance cycles with prey cycles.

The 2 reproductive strategies also reflect differences in genetic relatedness among the 5 species. Blue, yellowtail, and olive rockfish belong to the subgenus Sebastosomus. Black rockfish Sebastes melanops also belong to this subgenus and are generally considered to be the sister group of yellowtail rockfish (Kendall et al. 2000). Black rockfish also release larvae in winter months (January 27 to March 21 in laboratory experiments), and the larvae have large oil globules but small body size (mean notochord length $=4.46 \mathrm{~mm}$, mean oil globule volume $=0.00506 \mathrm{~mm}^{3}$; Berkeley et al. 2004). Gopher and kelp rockfish are likewise closely related to each other, belonging to the subgenus Pteropodus (revised by Li et al. 2006). With correlative data, it is not possible to discern whether the patterns we observed were a consequence of phylogenetic constraints or species adaptations to the reproductive environment. Under either scenario, the differences among species suggest a linkage of reproductive strategy with the timing of larval release and average oceanographic conditions during the season of parturition.

These results are consistent with the general lifehistory strategies of California Current residents proposed by Shanks \& Eckert (2005). They suggested that nearshore species generally spawn in spring/summer and have shorter pelagic-stage durations than do shelf/slope species, which spawn in winter months. These broad differences may promote return of settlement stages to parental populations in the context of the dynamic physical environment imposed by seasonal patterns of transport. Rockfishes of the subgenus Pteropodus comprise the most shoreward distributions of Sebastes spp. in the California Current, and have relatively short pelagic stage durations compared with other rockfishes (Love et al. 2002). In contrast, the Sebastosomus representatives we examined reside in slightly deeper shelf or slope habitats as adults and have relatively long pelagic-stage durations. Parturition in winter may help to avoid the intense offshore transport that arrives with the spring transition. Although Shanks \& Eckert (2005) suggested that starvation is less important than unfavorable transport in shaping the timing of reproduction for winter spawners, our results suggest that, in rockfishes, some shortterm insurance against starvation is provided by the greater lipid reserves of larvae released in winter compared with those released in spring/summer. Within the rockfishes, there are exceptions to the correspondence of spawning season with adult habitat, but detailed information on larval characteristics is needed if reproductive strategies are to be interpreted.

Our data are necessarily correlational, and with no overlap in parturition time between the winter- and spring-spawning species it is not possible to directly test the role of parturition time on species differences in larval traits. Likewise, we were not able to collect pregnant females for all species in all years. However, ANOVA comparisons of larval traits among years within each species did not indicate an effect of year of collection, suggesting that the traits were consistent among cohorts. We believe that the observed patterns comprise a parsimonious explanation for species differences. The majority of Sebastes species release larvae in winter months (Echeverria 1987). Further comparisons will be needed to determine if the apparent observed association of larval traits with the oceanographic environment is also evident for other species within the Sebastosomus and Pteropodus subgenera, as well as among the other subgenera of primarily winter-spawning rockfishes.

Within a species, variability in the timing of parturition may be related to maternal age or size. Bobko \& Berkeley (2004) found that older black rockfish released larvae earlier in the spawning season than did younger fish. Likewise, we observed a maternal effect on timing of parturition in blue, yellowtail, and kelp rockfish (Sogard et al. in press). This pattern will result in larvae from different mothers being subjected to oceanographic conditions that differ slightly but are within the general winter or spring conditions exploited by each species.

\section{Fecundity}

Regardless of parturition seasonality, traits of larval quality must interact with the additional trade-off of larval quantity. Natural selection should favor a compromise between the quality and quantity of offspring, be- 
cause these will invariably be negatively correlated (Smith \& Fretwell 1974, Ramirez Llodra 2002). However, our comparisons did not indicate a species difference in fecundity and did not reveal clear trade-offs between larval size or oil globule volume and either absolute or weight-adjusted fecundity. Overall, the fecundity of rockfishes is relatively high ( 18000 in the dwarf calico rockfish Sebastes dalli to 2700000 in yelloweye rockfish S. ruberrimus; Love et al. 2002). The primitive form of viviparity common to rockfishes retains high fecundity levels while providing clear survival advantages to egg and yolk-sac stages (Wourms 1991). Further work is needed to test for other potential trade-offs associated with fecundity in rockfishes, but these preliminary comparisons suggest that the trade-off within larvae between soma and lipid reserves may be hierarchically nested within the trade-off between total energy allocated to reproduction and the number of offspring.

\section{Larval performance traits}

Resistance to starvation

There was a significant trend of increasing survival with increasing oil globule volume, both among and within species. The importance of the TAG-rich oil globule in conferring resistance to starvation was previously noted for black rockfish by Berkeley et al. (2004). Larvae in their study had considerably larger oil globules (mean $=0.0051 \mathrm{~mm}^{3}$ ) than the species measured in this study, and showed a correspondingly greater survival. After re-calculation from their index of time to $50 \%$ mortality to our index of time to $75 \%$ mortality, black rockfish survived 7 to $14 \mathrm{~d}($ mean $=10)$ without food, compared with the 2 to $12 \mathrm{~d}$ observed here. Consistent with the trade-off between larval size and energy reserves, the large oil globules of black rockfish were matched by small notochord lengths, with a mean of $4.46 \mathrm{~mm}$, smaller than any of the 5 species examined in this study.

The extent to which Sebastes spp. larvae starve under natural conditions is unknown. However, for winter spawning species, the energy reserve available in the oil globule may provide vital insurance under unpredictable and patchy foraging opportunities. We maintained our holding and rearing tanks at $12^{\circ} \mathrm{C}$ in all of our experiments to control for temperature effects. Colder or warmer temperatures will respectively extend or reduce starvation resistance owing to changes in metabolic rate. The temperatures experienced by newly released larvae will be determined by oceanography at the location and time of parturition.

Maternal effects on oil globule size, with older females producing larvae with larger oil globules com- pared with larvae from younger females, were found in black rockfish (Berkeley et al. 2004). Similar effects were observed for blue, yellowtail, and gopher rockfish (Sogard et al. in press), explaining some of the variability in oil globule volume within species. This maternal effect suggests subtle differences in energy partitioning among larvae as females age, in concert with an apparent shift in parturition timing for some species. In contrast, maternal effects on larval size were not observed in any of the species we examined.

\section{Growth}

We found substantial differences among species in the time taken to initiate growth, with gopher and kelp larvae initiating growth 5 to $10 \mathrm{~d}$ earlier than blue rockfish larvae. Earlier growth coupled with a larger initial size led to a significantly greater size in gopher and kelp larvae compared with blue larvae at 1 mo of age. Thus, size differences evident at parturition were maintained 1 mo later. Larger body size throughout the larval period is important because body size influences vulnerability to predators through both escape ability and predator-gape limitation (Miller et al.1988). Modeling studies clearly show that growth and size differences among fish can substantially affect survival (Houde 1987, 1989, Winemiller \& Rose 1993, Letcher et al. 1996), influencing both individual as well as cohort success (Letcher et al. 1996). These theoretical considerations are also supported by numerous field studies that provide direct evidence of size-dependent mortality of larval and juvenile fishes in natural environments (Searcy \& Sponaugle 2001, Bergenius et al. 2002, Hoey \& McCormick 2004). Likewise, Takasuka et al. (2003) found that slower-growing larvae were more susceptible to predators independent of body size, suggesting that the better physiological condition of faster-growing larvae enhanced their escape abilities.

A lag prior to initiation of positive growth has not been previously described for rockfish larvae, but few studies have monitored growth on short time scales. This lag may be an artifact of the laboratory environment, or it may be a natural factor associated with the time needed by a larva to learn effective foraging behavior. As such, it suggests an additional factor of vulnerability for larvae immediately after parturition, regardless of the availability of prey.

\section{Startle performance}

Among species there were clear relationships between the startle response of larvae and their size, with the larger gopher and kelp larvae moving 
greater distances and at faster speeds compared with the smaller blue rockfish larvae, and with the intermediate-sized olive rockfish larvae exhibiting an intermediate response. The 3 performance measures are indicative of slightly different escape abilities of the larvae: average speed relates to their ability to escape a chasing predator, maximum speed relates to their ability to escape suctorial predators, and total startle distance influences the extent to which they move out of a predator's perceptual field (Williams et al. 1996). Taken together, their positive association with body size across species suggests that larger larvae will have substantially greater success in avoiding predation and are likely to do much better than smaller larvae under conditions of high predator density. Increasing escape capabilities with increasing body size have been commonly observed for larval fishes and amphibians (Batty et al. 1993, Williams et al. 1996, Fuiman et al. 1999, Wesp \& Gibb 2003, Eidietis 2005). We did not observe a correlation between larval size and startle performance within species, but this was likely due to the relatively narrow size range within individual species (CV ranged from 2.9 to $3.3 \%$ within a species, but was $6.0 \%$ for the means of each of the 5 species).

When converted to a relative scale (per unit body length), average swimming speeds during the startle response were similar for all species (approximately 17 to $18 \mathrm{bl} \mathrm{s}^{-1}$ ), were slightly slower than those recorded for subtropical fish larvae (20 to $30 \mathrm{bl} \mathrm{s}^{-1}$; Fuiman et al. 1999), and fell mid-range when compared with a broad range of teleost larvae measured at similar temperatures (Wesp \& Gibb 2003).

\section{Routine activity}

While startle responsiveness increased with body size, this was not true for routine swimming speeds, which were highly variable among species and among larvae from different females. Routine swimming speeds (per unit body length) were on the order of 0.6 to $1.0 \mathrm{bl} \mathrm{s}{ }^{-1}$, comparable with other temperate species (Hunter \& Kimbrell 1980) but somewhat slower than those of subtropical species (1 to $2 \mathrm{bl} \mathrm{s}^{-1}$; Fuiman et al. 1999) and substantially slower than the routine speeds of some tropical larvae $\left(1.5\right.$ to $6 \mathrm{bl} \mathrm{s}^{-1}$; Fisher \& Bellwood 2003). All swimming trials were conducted on the morning after parturition in the absence of food. The activity of larvae may be closely related to food stimuli (Hunter 1981) and may also vary in response to predators. It would be interesting to see if the activity level and responsiveness of larvae increases in the presence of food and/or predator stimuli.

\section{Conclusions and future directions}

Here we document a trade-off among rockfish species between the size and energy provisioning of offspring. These attributes differentially influence a suite of larval performance traits and suggest that cohort survival may vary substantially under differing environmental conditions. The patterns observed are readily interpreted in the context of the California Current ecosystem, where larvae are faced with contrasting circulation, upwelling, production, and transport conditions depending on season of parturition. Fine-scale trade-offs in progeny attributes that potentially have large effects on survival highlight that the consideration of multiple dimensions of larval quality may be necessary in order to appropriately assess offspring fitness when examinating life-history theory and predictions.

Investigation of additional species and populations, particularly those that reside in contrasting ecosystems, would help resolve the question of whether the 2 life-history patterns observed are related to phylogenetic history or reflect recent adaptations to seasonal oceanographic conditions. For example, larval traits for black rockfish residing in coastal waters of Alaska, where they experience a very different oceanographic regime dominated by downwelling processes, could provide a useful comparison with larval traits observed for a California Current population by Berkeley et al. (2004).

Rockfish have episodic recruitment success, and the early larval stage is thought to be essential in determining cohort strength (Ralston \& Howard 1995). Prior studies found non-random survival relative to parturition date in some annual cohorts (Yoklavich et al. 1996). Further study of this effect would provide insight into the interaction of larval traits and oceanographic conditions in determining cohort success or failure, and may prove invaluable in determining the extent to which rockfish species with differing lifehistory traits will respond to modifications of oceanographic regimes owing to climate change.

Acknowledgements. We thank Y. Vrugtman, R. Wiedling, N. Parker, P. Perasso, and M. Gleason for valuable assistance with mortality, growth and swimming experiments, and with aquarium maintenance and image analysis of larvae. E. Sturm provided expertise in the design and maintenance of seawater facilities at the Santa Cruz laboratory.

\section{LITERATURE CITED}

Batty RS, Blaxter JHS, Fretwell K (1993) Effect of temperature on the escape responses of larval herring, Clupea harengus. Mar Biol 115:523-528

Berg KO, Hendry PA, Svendsen B, Bech C, Arnekleiv VJ, 
Lohrmann A (2001) Maternal provisioning of offspring and the use of those resources during ontogeny: variation within and between Atlantic salmon families. Funct Ecol 15:13-23

Bergenius MAJ, Meekan MG, Robertson DR, McCormick MI (2002) Larval growth predicts the recruitment success of a coral reef fish. Oecologia 131:521-525

Berkeley SA, Chapman C, Sogard SM (2004) Maternal age as a determinant of larval growth and survival in a marine fish, Sebastes melanops. Ecology 85:1258-1264

Bjorkstedt EP, Rosenfeld LK, Grantham BA, Shkedy Y, Roughgarden J (2002) Distributions of larval rockfishes Sebastes spp. across nearshore fronts in a coastal upwelling region. Mar Ecol Prog Ser 242:215-228

Bobko SJ, Berkeley SA (2004) Maturity, ovarian cycle, fecundity, and age-specific parturition of black rockfish, (Sebastes melanops). Fish Bull 102:418-429

Boehlert GW, Yoklavich M (1984) Reproduction, embryonic energetics, and the maternal fetal relationship in the viviparous genus Sebastes (Pisces: Scorpaenidae). Biol Bull (Woods Hole) 167:354-370

Boehlert GW, Kusakari M, Shimizu M, Yamada J (1986) Energetics during embryonic development in kurosoi, Sebastes schlegeli Hilgendorf. J Exp Mar Biol Ecol 101:239-256

Cushing DH (1988) The study of stock recruitment. In: Gulland JA (ed) Fish population dynamics, 2nd edn. Wiley \& Sons, New York, p 105-128

Eaton RC, DiDomenico R (1986) Role of the teleost escape response during development. Trans Am Fish Soc 115: 128-142

Echeverria TW (1987) Thirty-four species of California rockfishes: maturity and seasonality of reproduction. Fish Bull 85:229-250

Eidietis L (2005) Size-related performance variation in the wood frog (Rana sylvatica) tadpole tactile-stimulated startle response. Can J Zool 83:1117-1127

Einum S, Fleming IA (1999) Maternal effects of egg size in brown trout (Salmo trutta): norms of reaction to environmental quality. Proc R Soc Lond B 266:2095-2100

Eldridge MB, Norton EC, Jarvis BM, MacFarlane RB (2002) Energetics of early development in the viviparous yellowtail rockfish. J Fish Biol 61:1122-1134

Elgar MA (1990) Evolutionary compromise between a few large and many small eggs-comparative evidence in teleost fish. Oikos 59:283-287

Fisher R, Bellwood DR (2003) Undisturbed swimming behaviour and nocturnal activity of coral reef fish larvae. Mar Ecol Prog Ser 263:177-188

Fuiman LA, Smith ME, Malley VN (1999) Ontogeny of routine swimming speed and startle responses in red drum, with a comparison of responses to acoustic and visual stimuli. J Fish Biol 55:215-226

Harper DG, Blake RW (1990) Fast-start performance of rainbow trout, Salmo gairdneri, and northern pike, Esox lucius. J Exp Biol 150:321-342

Hoey AS, McCormick MI (2004) Selective predation for low body condition at the larval-juvenile transition of a coral reef fish. Oecologia 139:23-29

Houde ED (1987) Fish early life dynamics and recruitment variability. Am Fish Soc Symp 2:17-29

Houde ED (1989) Subtleties and episodes in the early life history of fishes. J Fish Biol 35:29-38

Hunter JR (1981) Feeding ecology and predation of marine fish larvae. In: Lasker R (ed) Marine fish larvae. University of Washington, Washington, DC, p 33-79

Hunter JR, Kimbrell CA (1980) Early life history of Pacific mackerel, Scomber japonicus. Fish Bull 78:89-101
Kaplan RH (1980) The implications of ovum size variability for offspring fitness and clutch size within several populations of salamanders (Ambystoma). Evolution 34:51-64

Kendall A (2000) An historical review of Sebastes taxonomy and systematics. Mar Fish Rev 62:1-24

Laidig TE, Pearson DE, Sinclair LL (2003) Age and growth of blue rockfish (Sebastes mystinus) from central and northern California. Fish Bull 101:800-808

Lenarz WH, Ventresca DA, Graham, WB, Schwing FB, Chavez F (1995) Explorations of El Niño events and associated biological population dynamics off central California. Calif Coop Ocean Fish Invest Rep 36:106-119

Letcher BH, Rice JA, Crowder LB, Rose KA (1996) Variability in survival of larval fish: disentangling components with a generalized individual-based model. Can J Fish Aquat Sci 53:787-801

Li Z, Gray AJ, Love MS, Asahida T, Gharrett AJ (2006) Phylogeny of members of the rockfish (Sebastes) subgenus Pteropodus and their relatives. Can J Zool 84:527-536

Love MS, Yoklavich M, Thorsteinson L (2002) The rockfishes of the Northeast Pacific. University of California Press, Berkeley, CA

McEdward LR, Morgan KH (2001) Interspecific relationships between egg size and the level of parental investment per offspring in echinoderms. Biol Bull (Woods Hole) 200: $33-50$

Miller T, Crowder LB, Rice JA, Marschall EA (1988) Larval size and recruitment mechanisms in fishes: toward a conceptual framework. Can J Fish Aquat Sci 45:1657-1670

Moran AL, Emlet RB (2001) Offspring size and performance in variable environments: field studies on a marine snail. Ecology 82:1597-1612

Mousseau TA, Fox CW (1998) The adaptive significance of maternal effects. Trends Ecol Evol 13:403-407

Norton EC, MacFarlane RB, Mohr MS (2001) Lipid class dynamics during development in early life stages of shortbelly rockfish and their application to condition assessment. J Fish Biol 58:1010-1024

Parichy DM, Kaplan RH (1992) Maternal effects on offspring growth and development depend on environmental quality in the frog Bombina orientalis. Oecologia 91:579-586

Parker GA, Begon M (1986) Optimal egg size and clutch size: effects of environment and maternal phenotype. Am Nat 128:573-592

Parrish RH, Nelson CS, Bakun A (1981) Transport mechanisms and reproductive success of fishes in the California current. Biol Oceanogr 1:175-203

Pennington JT, Chavez FP (2000) Seasonal fluctuations of temperature, salinity, nitrate, chlorophyll and primary production at station H3/M1 over 1989-1996 in Monterey Bay, California. Deep-Sea Res II 47:947-973

Ralston S, Howard DF (1995) On the development of yearclass strength and cohort variability in two northern California rockfishes. Fish Bull 93:710-720

Ramirez Llodra E (2002) Fecundity and life-history strategies in marine invertebrates. Adv Mar Biol 43:87-170

Roesler CS, Chelton DB (1987) Zooplankton variability in the California Current, 1951-1982. Calif Coop Ocean Fish Invest Rep 28:59-96

Roff DA (1992) The evolution of life histories. Chapman \& Hall, New York

Ross JRM, Larson RJ (2003) Influence of water column stratification on the depth distributions of pelagic juvenile rockfishes off central California. Calif Coop Ocean Fish Invest Rep 44:65-75

Sakuma KM, Ralston S, Roberts DA (1999) Diel vertical distribution of postflexion larval Citharichthys spp. 
and Sebastes spp. off central California. Fish Oceanogr 8:68-76

Searcy S, Sponaugle S (2001) Selective mortality during the larval-juvenile transition in two coral reef fishes. Ecology 82:2452-2470

Shanks AL, Eckert GL (2005) Population persistence of California current fishes and benthic crustaceans: a marine drift paradox. Ecol Monogr 75:505-524

Sibly RM, Calow P (1986) Physiological ecology of animals. Blackwell Scientific, Oxford

Smith CC, Fretwell SD (1974) The optimal balance between size and number of offspring. Am Nat 108:499-506

Sogard SM, Berkeley SA, Fisher R (in press) Maternal effects in rockfishes (Sebastes spp.): a comparison among species. Mar Ecol Prog Ser

Stearns S (1992) The evolution of life histories. Chapman \& Hall, New York

Takasuka A, Aoki I, Mitani I (2003) Evidence of growth-

Editorial responsibility: Kenneth Heck (Contributing Editor), Dauphin Island, Alabama, USA selective predation on larval Japanese anchovy Engraulis japonicus in Sagami Bay. Mar Ecol Prog Ser 252:223-238

Wesp HM, Gibb AC (2003) Do endangered razorback suckers have poor larval escape performance relative to introduced rainbow trout? Trans Am Fish Soc 132:1166-1178

Williams PJ, Brown JA, Gotceitas V, Pepin P (1996) Developmental changes in escape response performance of five species of marine larval fish. Can J Fish Aquat Sci 53: 1246-1253

Winemiller K, Rose K (1993) Why do most fish produce so many tiny offspring? Am Nat 142:585-603

Wourms JP (1991) Reproduction and development of Sebastes in the context of the evolution of piscine viviparity. Env Biol Fish 30:111-12

Yoklavich MM, Loeb VJ, Nishimoto M, Daly B (1996) Nearshore assemblages of larval rockfishes and their physical environment off central California during an extended El Niño event, 1991-1993. Fish Bull 94:766-782

Submitted: October 24, 2006; Accepted: February 8, 2007 Proofs received from author(s): July 26,2007 